\title{
Alleviation Of Soil Acidity Improves The Performance Of Oil Palm Progenies Planted On An Acid Ultisol.
}

\begin{abstract}
Soil acidity is one of the main factors that limit profitable and sustained agricultural production. Oil palm (Elaeis guineensis Jacq.) is mainly planted in acidic soils. In the last years, there has been a stagnated yield and increases in disease incidence and severity worldwide that could be attributed in some extent to soil acidity. This study was conducted to determine the effects of soil acidity alleviation on oil palm seedlings. The effects of ground magnesium limestone or dolomite and magnesium carbonate $(0,1.1,2.2,3.3$ and $4.4 \mathrm{t}$ ha -1$)$ applied to an Ultisol dominated by kaolinite ( $\mathrm{pH}$ in water 4.4) were evaluated on selected morphological, physiological and nutritional characteristics of hybrid (Deli dura-AVROS pisifera) and clonal (clone 366) oil palm progenies under nursery conditions for 8 months. Increasing rates of ground magnesium limestone and magnesium carbonate showed a significant effect on improving soil $\mathrm{pH}$ and lowering exchangeable aluminium. The hybrid oil palm showed significant either linear or quadratic trends for most of the parameters evaluated, indicating that the best responses for morphological and physiological traits were achieved from 2.5 to 4.23 t ha -1 with ground magnesium limestone and 2.87 to 3.45 t ha -1 with magnesium carbonate. Positive effects of increasing rates of ground magnesium limestone and magnesium carbonate were observed on nitrogen and magnesium uptake. Aluminium concentration in the third frond decreased significantly with increasing ground magnesium limestone rate. A significant reduction of manganese uptake was also observed with increasing rates of both ameliorants. The clonal oil palm progeny exhibited a better performance on un-amended treatment. This may be explained by the significant higher root growth of this progeny. Soil acidity alleviation improved the oil palm seedling growth. These results are important for the oil palm industry and could be applied in the nursery stage as well as extended to the immature stage.
\end{abstract}

Keyword: Elaeis guineensis Jacq.; Liming; Magnesium; Oil palm; Photosynthesis; Soil acidity; Ultisols. 